Article

\title{
Nudging and Other Behaviourally Based Policies as Enablers for Environmental Sustainability
}

\author{
Marta Santos Silva
}

Citation: Santos Silva, Marta. 2022. Nudging and Other Behaviourally Based Policies as Enablers for Environmental Sustainability. Laws 11: 9. https://doi.org/10.3390/ laws11010009

Received: 16 November 2021

Accepted: 4 January 2022

Published: 25 January 2022

Publisher's Note: MDPI stays neutral with regard to jurisdictional claims in published maps and institutional affiliations.

Copyright: (C) 2022 by the author. Licensee MDPI, Basel, Switzerland. This article is an open access article distributed under the terms and conditions of the Creative Commons Attribution (CC BY) license (https:// creativecommons.org/licenses/by/ $4.0 /)$.
Research Centre for Justice and Governance (JusGov), School of Law, University of Minho, 4710-057 Braga, Portugal; marta.santossilva@direito.uminho.pt

\begin{abstract}
Recent years have shown that traditional regulatory techniques alone are not effective in achieving behaviour change in important fields such as environmental sustainability. Governments all over the world have been progressively including behaviourally informed considerations in policy and law making with the aim of improving the acceptance and impact of sustainability-oriented measures. This led to the arrival of alternative regulatory tools, such as nudges. The effectiveness of nudges for environmental sustainability (green nudges) has been widely reported, but the practical and ethical implications are still largely neglected by academic research. In this contribution, "nudges" are conceptually distinguished from "boosts" and their ethics are briefly explained. The analysis is made in light of European and US American academic literature.
\end{abstract}

Keywords: consumer behaviour; green nudges; boosts; sustainability; libertarian paternalism; sustainable consumption; human bias; ethics; proportionality; autonomy

\section{Introduction: The Rise of Nudges in the Policy Making Toolbox}

Prior to the rise of Behavioural Economics, policy and legal instruments focused exclusively on deliberative choice. It was believed that the ultimate motivation of people was money-hence, in order to direct people to comply with rules, they were given economic incentives (such as subsidies). Similarly, to discourage people from certain behaviours, they were subjected to economic disincentives (such as taxes, penalties, and fines).

The behavioural revolution in law and economics showed that price-based mechanisms have inherent limitations when it comes to achieving behavioural change (Yayun and Faure n.d.). Behavioural Economics established the insight that money sometimes has a negative effect on behaviour and that market failures may be caused by biases of individual decision making (Frey 1998). As for the former aspect, subsidies discourage the right action, as agents fear others will perceive them as motivated by money instead of moral values (Ariely et al. 2009). As for the latter aspect, agents may perceive money as a "green light" to misbehave, or a price they may opt to pay, leading to a reinforcement of the behaviour we intend to change (Gneezy and Rustichini 2000).

These data led policymakers to start considering non-monetary incentives, which showed that humans display a tendency to inertia and procrastination, are very sensitive to how information is framed and to the reputational damage that comes from not following social norms, and do not handle probabilities well (Alemanno and Sibony 2015).

Behavioural science is currently used or considered for use as a policy tool in the UN and in most of the 35 member countries of the OECD (Hertwig and Grüne-Yanoff 2017). Since 2010, the governments of The Netherlands, France, the United Kingdom, Denmark, Finland, the United States, Australia, New Zealand, Canada, Japan, Indonesia, India, Qatar, Saudi Arabia, and Singapore have set up national behavioural insights entities. In 2015, the World Bank launched GINI, the Global Insights Initiative, a team that incorporates behavioural and social insights into the World Bank Group, and in 2020, the World Health Organisation created a Behavioural Insights Unit (Thaler and Sunstein 2021). 
These recent developments show the significance of insights from the behavioural sciences in helping policymakers increase the efficiency of their directives.

\section{The Use of Green Nudges by EU Policymakers}

The use of behaviour insights has been particularly noteworthy in the field of environmental protection.

Private consumption is responsible for more than a quarter of all greenhouse gas emissions (Thorun et al. 2017), so the change in consumption patterns has significant potential to help fight climate change and achieve environmental sustainability. Nevertheless, the use of behaviourally based approaches was not used parallelly to more traditional regulatory instruments until recent times.

Environmental regulation typically comprises several regulatory techniques that range from command-and-control instruments relying on criminal and administrative enforcement to market-related mechanisms such as environmental taxation, subsidies, tradable allowances and deposit schemes, participatory-based regulation, and self-regulatory schemes (Feldman and Perez 2009). It has long been thought that these methods, sometimes named "anti-nudges" (Sunstein 2009), were the best way to reduce environmental harm (Vankatachalam 2008).

However, empirical studies have demonstrated that traditional methods are partially ineffective (Sunstein and Reisch 2014) in pursuing environmental protection. Conversely, other studies (Bruns et al. 2018; Schubert 2017; Dworkin 2016) have shown the efficacy of "nudge-like" instruments, which comprise several incentives: information disclosure, warnings, social norms, and default rules (Sunstein 2021). Even though their effects require further study (Osman and Baddeley 2019), some studies show that nudges are efficient in altering people's behaviours (Thaler and Sunstein 2021), particularly in the areas of waste management and resource efficiency (Nielsen et al. 2016). Allegedly, these generate less resistance from the target citizens than traditional regulation (UK Cabinet Office n.d.).

Green nudges have been used in several countries (OECD 2017; Schubert 2017) and at the European Union level.

In the EU Green Agenda, a set of EU policy initiatives for achieving climate neutrality by 2050 effecting changes in consumer behaviour enjoy a high priority. The EU Green Deal intends to reach climate neutrality through the implementation of carbon pricing (a traditional monetary incentive), and consumer empowerment to encourage sustainable choices. In this regard, one of the measures aimed at empowering consumers is access to reliable information on product repairability and durability, which may (or may not) be behaviourally informed.

At a more global level, the 2030 Agenda for Sustainable Development aims at reaching very ambitious goals in less than a decade, so there is a pressing need to render outcomes more effective (UN Nations 2017).

The reason why policymakers are turning to nudges lies in their capacity to change human behaviour, to be explained in the subsequent section.

\section{Nudge}

\subsection{Definition and Typology}

In their seminal work on nudging, Richard Thaler and Cass Sunstein defined the term "nudge" as "any aspect of the choice architecture [ . . ] that alters people's behaviour in a predictable way without forbidding any options or significantly changing their economic incentives" (Thaler and Sunstein 2021). This is a relatively broad definition, coined in the first edition of Nudge and kept throughout the subsequent papers and books of its authors, including "The Final Edition of Nudge, dated August 2021.

When deconstructed, the definition of a nudge seems to imply four main aspects:

1. A change to the choice architecture;

2. The change to a behaviour;

3. An undisturbed choice set; and 
4. The absence of monetary incentives.

As for the first requirement, choice architecture may be defined as the context within which agents take decisions (Tor 2016). Nudges provide for a change in this context according to insights of behavioural sciences. The aim is to induce behavioural change (second requirement). The third requirement consists of one of the raisons d'etre for which its founders and supporters swear for (Thaler and Sunstein 2021). Nudges imply both that no options are forbidden and that none are imposed (Sunstein 2009). Finally, nudges do not involve monetary incentives (Reijula and Hertwig 2020). If a store offers a discount when shoppers buy earth-friendly products, this is a purely economic incentive and cannot be considered a nudge. For example, the conception of the deposit for plastic bottles has been a behaviourally based measure, which rightly considered that consumers are affected by loss aversion and are thus inclined to cooperate in the recycling of these bottles. However, because it does involve a monetary incentive for consumers (the return of the fee that they had paid for the bottle upon purchase of the good), the measure cannot be considered a nudge.

Several typologies of nudges can be found in the academic literature.

According to one classification (Di Porto and Rangone 2015), there are three categories of nudges: default rules, smart information nudging, and exploiting/neutralising emotional responses. Default rules, i.e., the options that prevail when people do not engage in active choice (Sunstein and Reisch 2014), are highly effective. They exploit inertia, implicitly endorse a given choice, and, whenever potential gains or losses of making a choice are unclear to deciding agents, make the default's acceptance the preferred option. Smart information nudges use knowledge about framing, salience, and social influence to provide data to consumers in a "relational" way (the "tell people what you are doing" strategy). Experiments with energy use in the context of which individual consumption among neighbours is compared and disclosed, and others that demonstrate that people recycle more and better when their recycled bins receive "golden stars" show the importance that consumers give to social recognition and reputation. Finally, another subset of nudges seeks to exploit, often in an undisclosed manner, the emotional responses of individuals. They co-opt the decision maker's cognitive processes, taking advantage of some pattern of irrationality (Bovens 2009) to rearrange preferences (Hertwig and Grüne-Yanoff 2017).

\subsection{Libertarian Paternalism and Ethical Objections}

The authors of Nudge claim that a philosophy entitled "libertarian paternalism" is at the heart of nudging (Thaler and Sunstein 2021). On the one hand, the nudge is paternalistic, as it stimulates choices that are perceived as welfare-enhancing for the individual; on the other hand, the nudge is libertarian, because, according to its supporters, it is a "relatively weak" and "nonintrusive" type of paternalism (Thaler and Sunstein 2021) — the agent remains free to decide on the preferred course of action (Cserne 2015).

Libertarian paternalism has been subject to widespread criticism (Thaler and Sunstein 2021). It has been famously classified as an "oxymoron" (Mitchell 2004; cp. Sunstein and Thaler 2003) and accused of infringing the "autonomy-freedom" of the individual (Guala and Mittone 2015), as opposed to the "option-freedom" that it would respect (cp. Cserne 2015) by leaving the choice set of the deciding agent essentially unchanged (Hertwig and Grüne-Yanoff 2017; Nielsen et al. 2016; Oliver 2015; van Aaken 2015). Additionally, by stating that libertarian paternalism lies at the heart of nudges, Thaler and Sunstein seem to imply that nudges are always paternalistic. However, this is not the case, even in the view of the authors themselves, who include several examples of socially oriented nudges, namely towards environmental protection (Thaler and Sunstein 2021).

\section{Boost}

\subsection{Definition and Distinction from Nudge}

Behavioural science is mainly associated with nudges (Oliver 2015), but there is another broad category of policies or interventions that, based on psychological insights 
(Schubert 2015a), structure choices in such a way that people are more prone to make a choice that is either in their interest or that of a third party (Bovens 2009). That is the case with "boosts" (Hertwig and Grüne-Yanoff 2017).

Nudges and boosts are both based on empirical evidence of substantial and diffused cognitive and behavioural limitations (Di Porto and Rangone 2015) and they both aim at modifying an individual's behaviour. Neither implies a financial incentive, and both claim to leave freedom of choice untouched, while being cheaper than more traditional instruments.

They differ in the target of the intervention and the causal pathways taken to prompt the change of behaviour. On the one hand, nudges are cognitive-based regulatory strategies meant to exploit, often in an undisclosed manner, the emotional responses of individuals. They co-opt the decision maker's cognitive processes, so they target behaviour directly taking advantage of some pattern of irrationality (Bovens 2009) to rearrange preferences (Hertwig and Grüne-Yanoff 2017). On the other hand, boosts are rational-based regulatory strategies meant to enhance people's capacity to manage emotional responses by overcoming biased thinking and non-deliberative choice (Jolls and Sunstein 2005), as well as to adopt deliberately conscious and considerate decisions. Thereby, while nudge strategies are deemed as bias-preserving, boosts are considered de-biasing techniques (Di Porto and Rangone 2015; cp. Jung and Mellers 2016), aimed at improving people's competence to exercise their agency (Hertwig and Grüne-Yanoff 2017).

\subsection{Taxonomy}

\section{Legal Scholars Provide for Different Classifications of Boosts}

Hertwig and Grüne-Yanoff, for example, subdivide boosts according to the competence to be boosted and the target audience. As for the former, they can be further sub-classified into risk literacy boosts (that establish or foster competence to understand statistical information), uncertainty management boosts (that establish or foster procedural rules for making good decisions, predictions and assessments under uncertain conditions with the help of simple actuarial inferential methods, simple rules of collective intelligence, fast and frugal decision trees, simple heuristics, and procedural routines), and motivational boosts (that foster the competence to autonomously adjust ones motivation, cognitive capacity, and self-control). As for the latter, boosts can affect the population at large scale or a subset thereof, people up to or after a certain age, etc. (Hertwig and Grüne-Yanoff 2017).

Di Porto and Rangone (Di Porto and Rangone 2015) distinguish between five types of boosts (rectius, in their expression "empowerment" techniques): simplification of information, framing of information and priming (Reijula and Hertwig 2020), targeted education, simplification of choices, and overcoming emotional responses.

Simplification of information may be accomplished through reducing information and selecting the "really informative" one (i.e., the data that would lead to a behaviour change); attention is a scarce resource and information overload might consume it. Due to the framing effect bias, the perception of the desirability of an option by individuals can change by the way the information is presented or framed (Feldman 2018). In the context of household appliance labelling, "relative information" such as scales, particularly when combined with colours, is more intuitive and effective in facilitating choice about energyefficient products than information presented in a technical or statistical format. Traditional information disclosure has proven insufficient to change one's habits, so targeted education not only provides information but also educates individuals how to better process it.

Another boost consists of the simplification of choices, which can be exercised, for example, through "pro-choice" web applications required by impartial, public authorities to the private sector. This tool may prove effective in overcoming inertia and status quo biases, and measure the increase in the consumer's ability to make good choices. We can expect Big Data to considerably widen the realm of applications in this domain soon (Schubert 2015a).

Yet another boost is to overcome emotional responses. The contractual "cooling-off period" is one example of an externally implemented method. This strategy is intended 
to help people make considered choices and overcome emotional responses, based on a waiting period being imposed by the regulator before a final decision is made.

Most of these boosts can also be self-deployed. They are named "notes to self", "self-nudges" (Reijula and Hertwig 2020), or "sophisticated choice" (Bovens 2009). Selfboosts are (self-)paternalistic and empowering interventions that enable people to design and structure their own decision environments - that is, to act as citizen choice architects (Reijula and Hertwig 2020). Take the example of someone reducing the cow meat they consume to avoid contributing to greenhouse emissions. This person may decide to hang a picture depicting global warming in a fridge magnet together with the grocery list to discourage them from buying such meat (Moskin et al. 2019), thereby using the biases of framing and priming to reinforce their self-control.

\section{Classifying Both Nudges and Boosts}

\subsection{Based on the Affected Cognitive System}

As outlined by Nobel laureate Daniel Kahneman (Kahneman 2011), people use two cognitive systems for collecting information and for making decisions: system 1 (automatic system), a quicker, intuitive, and more impulsive/emotional system; and system 2 (effortful system), a slower, non-emotional, rule-governed system, which demands more reflection (Hertwig and Grüne-Yanoff 2017) and is therefore less relied upon in daily life for collecting information and making decisions.

The impact of the existence of these two systems in decision making is that people quite commonly act as irrational agents who take decisions while under the influence of several cognitive and psychological biases (Busch 2016). Therefore, instead of deciding rationally when given correct and sufficient information, as the "Econs" — a reference to homo economicus (Schubert 2015a) that Thaler and Sunstein mention in their "Nudge" bestseller book (Thaler and Sunstein 2021)_would, people are constrained by limitations of information and/or attention, cognitive capacity, and self-control (Hertwig and GrüneYanoff 2017; Cserne 2015).

Attempts to change behaviour can thus harness system 1 or foster system 2 routes. As has been mentioned, nudging predominantly takes the former approach (Hertwig and Grüne-Yanoff 2017), where boosts take the latter.

\subsection{Based on Their Paternalistic or Welfarist Goal}

Paternalism has been defined as "the interference of a State or an individual with another person, against their will, and defended or motivated by a claim that the person interfered with will be better off or protected from harm" (Dworkin 2010).

Indeed, based on cognitive limits and biases, people tend to take decisions that do not serve their welfare (Baldwin 2014) or that of society. In the first case, we are confronted with paternalistic "nudges"; in the second case, we are confronted with non-paternalistic "nudges". Paternalistic "nudges" promote individuals' well-being, while non-paternalistic "nudges" advance social goals, reducing third party externalities in the process. Regarding non-paternalistic nudges, where some may consider that making allocative choices between the rights of ones and others is a core prerogative of states and thus needs no special justification (van Aaken 2015), an analysis of the legal impact of non-paternalistic "nudges" is required.

Some "nudges" may advance both individual and social welfare. As long as their primary target is social welfare, they shall be classified as non-paternalistic. For example, energy-saving nudges are not primarily paternalistic since they ultimately target protecting the environment and energy saving and not the consumer's purse (van Aaken 2015). They should thus be considered non-paternalistic "nudges".

\subsection{Based on the Agent}

"Nudges" can be developed and/or implemented by all types of actors, namely companies, NGOs, public entities, individuals, and ourselves. 
All of them might be involved with both paternalistic and non-paternalistic "nudges", the latter involving also purely egotistical "nudges", such as in the typical case of marketing industry "nudges".

\section{Typology of Green "Nudges"}

A variety of nudges are discussed in the literature, some of which "lack consistency" (Hausman and Welch 2010).

As mentioned previously, even though one can also justify green nudges on paternalistic grounds (for instance, the use of renewable energy or the deployment of more minimalist consumption patterns can reduce spending), they shall be deemed non-paternalistic nudges (Schubert 2017).

An interesting and distinctive element of green nudges, as compared to other nonpaternalistic nudges, is the fact that we can reasonably argue they are aimed at promoting the welfare of both present and future generations (Hage 2019). There are different typologies, but we consider below the one proposed by Schubert given its clarity and comprehensiveness.

\subsection{Nudges That Appeal to People's Self-Image or Self-Identity}

By appealing to people's self-image or self-identity as "pro-environmental consumers" people can be nudged into adopting environmentally beneficial behaviours.

This can be achieved either by simplifying the way the information on a product's characteristics is provided; by increasing the salience of certain features, thereby making consumers more aware of them (for example, through eco-labels); or by harnessing people's private sense of "social identity". An example of such a nudge is the slogan "Don't mess with Texas", part of a social advertising campaign initiated in the 1980s for reducing litter in highways that appealed to the sense of community in this US state (Schubert 2017).

\subsection{Nudges That Appeal to Social Conformism}

These nudges take advantage of people's inclination to imitate the behaviour of their peers ("follow the herd" tendency). These nudges sometimes convey certain norms through peer comparison. A study by Goldstein and others (Goldstein et al. 2008) showed that placing a note into the bathroom of a given hotel indicating the overall percentage of clients who reuse their towels ("Join your fellow guests in helping to save the environment") could increase rates of towels reuse by almost $10 \%$.

Other nudges of this kind work by stimulating social status competition through, for example, encouraging consumers to signal green behaviour to others (Schubert 2017). One example is a programme implemented in the U.K. that rewarded citizens in a community who would recycle more with golden stars, which would be placed in their rubbish bins. The study concluded that neighbours increased their recycling levels following that program.

\subsection{Nudges Involving the Modification of Defaults}

Pro-environmental behaviour can be fostered by carefully setting the default (UK Cabinet Office n.d.; Sunstein and Reisch 2014). Setting defaults (Pichert and Katsikopoulos 2008), green defaults, has shown to be a particularly effective nudge (Sunstein 2021; Schubert 2017) because it seizes two biases: the powers of inertia and suggestion. As for inertia, if, for example, people are automatically enrolled in green energy, they are likely not to opt out (Sunstein 2021) because doing so would require the engagement of system 2. As for suggestion, default rules contain an informational signal, which may motivate compliance by consumers (Sunstein 2021). For example, an empirical study shows that consumers were more willing to pay for measures that compensate for the impact in their own consumption of $\mathrm{CO}_{2}$ emissions if the default option was the opt-out (Araña and Léon 2013). 


\section{Ethical and Practical Problems of Nudging and Boosting}

\subsection{Impact on Autonomy}

\subsubsection{Demand for Transparency}

Nudges and boosts are regulatory instruments that are expected to be legitimate and effective. However, a few reported consequences have been generating resistance to these tools-in other words, "nudge scepticism" (Cserne 2015). Such scepticism derives particularly from the fact that nudges are said to have a detrimental impact in the autonomy of those being nudged (Grüne-Yanoff and Hertwig 2015; Hausman and Welch 2010). Because nudges exploit cognitive limitations or biases, they shape behaviour in ways other than rational persuasion (Hausman and Welch 2010) that are not always transparent to the chooser (Reijula and Hertwig 2020).

Nudges are supposed to work in a transparent manner (Thaler and Sunstein 2021), but it is traditionally argued that the disclosure of the practice of nudging that transparency towards agents would require-and that would consist of informing consumers about the non-conscious processes by which the nudge intervention works-would affect their effectiveness as they "typically work better in the dark" (Reisch et al. 2017; Bovens 2010).

Recent studies (e.g., Bruns et al. 2018) have been showing that when made transparent, nudges are still found to be acceptable by the agents whose behaviour is being changed (Bruns et al. 2018; cp. Jung and Mellers 2016), even though surveys show some preference for nudges that affect system 2 rather than system 1.

Specifically regarding green "nudges", a meta-study prepared for the European Commission concluded that direct appeals to consumers that explicitly mention the environment are relatively ineffective and should therefore be avoided when designing green nudges (Schubert 2017).

The lack of transparency (Cserne 2015) raises one main concern: the fact that the nudge is not being disclosed to the person being nudged bypasses its reflective or deliberative processes and can be seen to undermine autonomy (Reijula and Hertwig 2020). Nudging, particularly paternalistic nudging, faces many objections within this domain, such as the violation of consumer sovereignty and the condescendence that comes with it (Schubert 2017).

\subsubsection{Doctrinal Spectrum of Autonomy}

There seems to be a spectrum as far as the importance of autonomy is concerned. On one end of the spectrum, we have those who minimise the detrimental effects of behaviourally informed interventions on autonomy, sometimes even arguing that these contribute positively to it. On the other end of the spectrum, we have those who consider autonomy an absolute value.

Autonomy is a quintessential domain of liberal thinking, something stressed by Stuart Mill in his pioneer work On Liberty and according to which individuals have the authority "to demand, within certain limits, that they be allowed to make their own choices for themselves".

In line with this harder approach to autonomy, contemporary authors Hausman and Welch and Bovens demand a level of self-knowledge or self-transparency on the part of the individual that "cannot be found in a behavioral world" (Hausman and Welch 2010; Bovens 2009). However, there are more nuanced approaches. Buss argues that either acting in accordance with one's character or with conditions of "minimal human flourishing", objectively defined, makes an individual act autonomously (Buss 2012). Other authors consider that only nudges of a certain degree would affect the autonomy of the consumer (Baldwin 2014). That is the case of Baldwin.

In the framework he proposes, there are three degrees of impact on the autonomy of the person being nudged, that raise different, and identifiable, concerns, some of which can be responded to in positive terms (Baldwin 2014). "First-degree nudges" respect the decision-making autonomy of the individual and enhance reflective decision making. Typical first-degree nudges involve the supply of simple information to individuals or 
the imparting of reminders (such as "there are three weeks left to complete your tax return"). Such nudges can be distinguished from "second-degree nudges" and "thirddegree nudges". A "second-degree nudge" typically builds on behavioural or volitional limitations to bias a decision in the desired direction. Finally, a "third-degree nudge" offers "a yet more serious intrusion on autonomy because it involves behavioural manipulation to an extent that other nudges do not" (Baldwin 2014).

On the most optimistic and less critical end of the spectrum, Sunstein, one of the creators of "nudge", argues that autonomy is a mere "heuristic" (Sunstein 2014a) and even that "nudges" promote autonomy (Sunstein 2014b) because they are specifically designed to ensure that choices are informed, and "autonomy requires informed choices" (Sunstein 2015). According to this argument, nudges seek to influence people's choices to make them better off as judged by themselves. By doing so, they improve the authenticity of a person's behaviour and thus provide a practicable method of empowerment (GrüneYanoff and Hertwig 2015).

In an attempt to address criticism to "nudges" based on their detrimental impact on autonomy, Sunstein speaks of "thin" and "thick" versions of autonomy. The former suggests that "freedom of choice is an ingredient of welfare" and we must thus consider the impact of public interference with such freedom (Sunstein 2013). Concerning this, on the one hand, individuals themselves might know better what is best for them than public officials; on the other hand, they might prefer to delegate some choices to them (Sunstein 2013). The thick version stresses that freedom of choice is an end in itself and thus should be overridden only for the most compelling reasons (Sunstein 2013).

\subsubsection{Autonomy within Self-Nudging and Boosts}

As for self-nudging specifically, like other policy tools, it has its limitations. Selfnudges require active participation from the developer/recipient of the nudge. Additionally, it is still unclear how efficient self-nudging interventions can be designed. Nevertheless, because people are educated to nudge themselves, self-nudging does not give rise to concerns about individual autonomy. Making mistakes and learning from them may play an important role in personal growth (Rebonato 2012), but self-nudging can even be understood as enhancing rather than undermining autonomy (Reijula and Hertwig 2020).

As for boosts, because they do not explore cognitive limitations or biases, they also do not seem to raise concerns about individual autonomy.

Boosts require the individual's active cooperation. They therefore need to be explicit, visible, and transparent. This leads to the fact that boosts are more respectful of autonomy than nudges (Hertwig and Grüne-Yanoff 2017; Sunstein 2015). Indeed, boosts have the goal of preserving personal agency and enable individuals to exercise that agency. Thus, if people endorse the objectives of a boost, they can choose to adopt it; otherwise, they can reject it (Hertwig and Grüne-Yanoff 2017).

Some interventions such as "cooling-off" periods and mandated choice merely counteract foibles in decision making without pushing individuals to choose one alternative rather that another. In this manner, shaping apparently enhances rather than threatens an individual's ability to choose rationally. Allowing people to voluntarily place themselves on a list that bans them from casinos shifts the decision to gamble towards a moment when temptation is weaker and thereby shapes the choice that results. However, it does not threaten people's control over their own choices (Hausman and Welch 2010).

\subsection{Reversibility and Sustainability}

Concerns about autonomy are amplified by related worries about reversibility. One defining condition of a nudge is that its effects must be easy for the targeted individual to reverse. However, reversibility in principle is not the same as reversibility in practice.

Self-nudges escape this reversibility-effectiveness dilemma to a large extent, as even self-nudges that are difficult to reverse do not involve the power asymmetry characteristic of nudges in which an assumedly naive decision maker faces a knowledgeable policymaker 
(Reijula and Hertwig 2020). Boosts do not explore system 1 and thus, options are much more real and approachable.

The choice architecture approach neglects the behavioural implications for long-term perceptions and sustainability of policy" (Feldman and Lobel 2015).

Nudges are, by design, local solutions restricted to particular choice settings and thus hardly scalable (Feldman and Lobel 2015). Consequently, policymakers are typically only able to influence public choice contexts by nudging. In private, individuals' self-control may be weakened (Reijula and Hertwig 2020), which makes some authors argue that when the values we aim to protect are as important as health or the environment, harder tools might need to be used. For example, Stern and others (Stern et al. 2010) compute that utility grant programs have the potential to reduce carbon emissions by $123 \mathrm{Mt}$ per annum, compared to $12.7 \mathrm{Mt}$ savings generated through peer comparison measures (Alcott and Mullainathan 2010).

Self-nudging brings previously inaccessible personal choice contexts into the realm of benevolent design and permits us also to focus on repeated rather than one-off behaviours, which are often the target of nudging interventions (Reijula and Hertwig 2020). Repetition may lead to a steady, progressive change towards the desired behaviour. By deploying system 2, boosts are likely to lead to sustainable choice change (Ralph 2017) by the deciding agents.

As far as sustainable behaviour is concerned, change through nudges is only effective where individuals exhibit limited mental resources (Slovic 1995; Ariely and Loewenstein 2006): they might be ineffective with regard to "bad people", those who know what they are doing and why. Nudges are also reported to lose effectiveness if agents feel manipulated (Rebonato 2012)_fairness is a dominant factor in human motivation (Feldman 2018).

In relation to boosts, sustainable behaviour can only be reached if people (Feldman 2018) are motivated to comply with "change for good" (their own or that of society as a whole). People's willingness to engage in social enforcement depends on their moral profile and the perception of efficiency of the regulatory instrument use (Feldman and Perez 2009). Concerning the former, it is those who see themselves as "good people", individuals who are naturally inclined to pro-social behaviour namely due to genuine empathy-altruism (Batson 1987), or by egotistical motivations (Cialdini 1991) who should have the attention of ex ante both traditional and non-traditional, behaviour-based legal intervention (Feldman 2018).

From the perspective of behavioural economics (different from behavioural morals), this not relevant, as in both cases, they are propense to the same goal.

Following a classification by Feldman, these are the "authentic good people", the "erroneous wrongdoers" (Feldman 2018) who unknowingly understand reality in a biased way and thereby behave in an undesired way, and "situational wrongdoers" who use various justifications to justify sporadic bad actions to avoid feeling immoral (Feldman 2018). "Calculative wrongdoers" should be dealt with ex ante with disincentives for acting and ex post through sanction. Behaviour intervention would here be likely to fail and/or to be considered illegitimate, for going against the will of the individual.

\subsection{Impact on Self-Legislation}

One of the claimed risks of "green nudges", particularly if they were to be used exclusively, is that they might deprive the society of the chance to engage in self-legislation (Lepenies and Malecka 2015) or self-command (Bovens 2009), meaning the control a social collective has over its evaluation, deliberation, and choice of social institutions.

Indeed, some claim that nudges can lead to "corrosion and ultimately corruption of public life" (Furedi 2011) to "long-term infantilisation" (Sunstein 2013; Bovens 2009), a situation where people become incapable of being master of their fates and make changes in their agency to compensate for the intention/action gap.

Irrespective of how well-intentioned government efforts to shape choices may be, there is a real concern with the risk that exploiting decision-making foibles will ultimately 
diminish people's autonomous decision-making capacities (Hausman and Welch 2010). In such measures, it has been considered that a constitutional framework should be agreed upon that monitors the way policymakers and bureaucrats use nudges in general and green nudges in particular (Schubert 2014; Schnellenbach 2016).

\subsection{Fairness of Green Nudges}

This argument respects the political feasibility of implementing these tools.

First, we must ask ourselves to what extent nudges redistribute either well-being or freedom among the heterogeneous population exposed to its effects (Schubert 2017). Some authors (Lehner et al. 2016) argue that "it is democratically worrying to use nudging to influence the behavior of those not able to identify it (and thus avoid it) escape the costs while benefitting from the gains" (Schubert 2017; Engel and Kurschilgen 2020).

Second, green nudges may give rise to a problem with the way that the roots of society's problems are perceived. The widespread implementation of these nudges could lead to a culture where the mindsets of individuals take the blame for all social ills (Schubert 2017). Green nudges thus risk promoting an individualistic approach that overlooks the deeper socio-cultural roots of the environmental problems that are to be addressed (Schubert 2017).

\subsection{Preference Identification}

A necessary condition for a nudge to be successful (not just harmless) is that the policymaker knows what makes choosers better off, namely by their own standards. In the impossibility of the policymaker obtaining reliable information about the chooser's true preferences, it is not safe to assume that policymakers know them (Guala and Mittone 2015; Schubert 2017) and/or know to adequately process them: public officials developing these interventions are, like the objects of these measures, traditionally prone to biases and heuristics (Cserne 2015). This is particularly so when the targeted population of decision makers has heterogeneous preferences (Grüne-Yanoff and Hertwig 2015), as short-term impulsive desires compete with long-term goals (Reijula and Hertwig 2020), preferences that are inconsistent (Sugden 2008; Angner 2016; Schubert and Cordes 2013; Schubert 2015b) over time, incoherent, or incomplete (Schubert 2017), or when the behaviour that is to be changed is the result of collective processes and policies (Furedi 2011) —it is argued that the way individuals answer to nudges depends on the cultural, economic, social, and institutional context of the agent and that they can easily "counter-nudge" (Baldwin 2014). This argument seems to be less relevant in relation to non-paternalistic nudges. When citizens adopt environmentally malignant behaviours, they are inflicting damages onto others, so their judgements about their welfare are not complete (Sunstein 2009). Additionally, the choice-architectural default norms seem to be detrimental to the environment.

It is unknown how self-nudging could help with tackling the problem of preference identification: how (and when) does a person know what they ultimately want or need? Behavioural science research suggests some methods for clarifying one's goals, but selfnudge can be perfectly neutral with respect to the internal process of bargaining between conflicting desires. As for boosts, they would usually present the same problems as nudges in this context.

\section{Discussion and Conclusions}

The considerations mentioned above lead us to conclude this paper with the following three theses:

1. Ensuring transparency is vital to ensure that nudges are legitimate, a key step any behaviourally informed environmental policy should make in the future to make green nudges ethical, even when doing so undercuts their effectiveness. We suggest implementing the criterion of "token transparency", proposed by Bovens (Bovens 2009): nudges should only be deemed ethically legitimate to the extent that they are devised in a way that it is possible, in principle, for everyone who is watchful to "unmask 
the manipulation". This would protect individuals who wish to resist the nudge and keep government in check.

2. As for boosts, the moral predisposition of individuals should be considered before such (often expensive) tools are deployed, as these can be effective only for individuals who are not immoral.

3. We follow the academic stream (Dietz et al. 2009; Ferraro and Miranda 2013; Lehner et al. 2016) in considering that green nudges should be seen, in principle, as complements rather than substitutes for traditional incentive-based measures, aiding the regulator in expanding the regulatory toolbox through collaborative regulation (Feldman 2018). The choice of a regulatory strategy should rather be made on a case-by-case basis and boosting should ideally precede nudging.

Funding: This research received no external funding.

Acknowledgments: The author would like to thank Yuval Feldman (Bar-Ilan University, Faculty of Law) and Hugo Schally (European Commission, DG Environment) for their insightful comments on an initial draft of this paper, the peer-reviewers for their useful comments as well as Prashant Sabharwal (Maastricht University) for the language control. All mistakes remain my own.

Conflicts of Interest: The author declares no conflict of interest.

\section{References}

Alcott, Hunt, and Sendhil Mullainathan. 2010. Behavior and Energy Policy. Science 327: 1204-5. [CrossRef] [PubMed]

Alemanno, Alberto, and Anne-Lise Sibony, eds. 2015. Epilogue: The Legitimacy and Practicability of EU Behavioural Policy-Making. In Nudge and the Law: A European Perspective. Oxford: Hart, pp. 325-47.

Angner, Erik. 2016. A Course in Behavioral Economics. London: Palgrave.

Araña, Jorge, and Carmelo Léon. 2013. Can defaults save the climate? Evidence from a field experiment on carbon offsetting programs. Environmental and Resource Economics 54: 613-26. [CrossRef]

Ariely, Dan, and George Loewenstein. 2006. Tom Sawyer and the construction of value. Journal of Economic Behavior Organisation 60: 1-10. [CrossRef]

Ariely, Dan, Anat Bracha, and Stephan Meier. 2009. Doing good or doing well: Image motivation and monetary incentives in behaving socially. American Economic Review 99: 544-55. [CrossRef]

Baldwin, Robert. 2014. From regulation to behaviour change: Giving nudge the third degree. The Modern Law Review 77: 831-57. [CrossRef]

Batson, Daniel. 1987. Prosocial motivation: Is it ever truly altruistic? Advances in Experimental Social Psychology 20: 65-122.

Bovens, Luc. 2009. The ethics of nudge. In Modelling Preference Change: Perspectives From Economics, Psychology and Philosophy. Edited by Till Grüne-Yanoff and Sven Oven Hansson. Berlin: Springer, pp. 207-19.

Bovens, Luc. 2010. Nudges and Cultural Variance: A Note on Selinger and Whyte. Knowledge, Technology E Policy $23: 483-86$.

Bruns, Hendrik, Elena Kantorowicz-Reznichenko, Katharina Klement, Marijane Luistro Jonsson, and Bilel Rahali. 2018. Can nudges be transparent and yet effective? Journal of Economic Psychology 65: 41-59. [CrossRef]

Busch, Christoph. 2016. Chapter 10: The future of pre-contractual information duties: From behavioural insights to big data. In Research Handbook on EU Consumer and Contract Law. Edited by Christian Twigg-Flesner. Cheltenham: Edward Elgar, pp. 221-240. [CrossRef]

Buss, Sarah. 2012. Autonomous action: Self-determination in the passive mode. Ethics 122: 647-91. [CrossRef]

Cialdini, Robert B. 1991. Altruism or Egoism? That is (still) the question. Psychological Inquiry 2: 124-26. [CrossRef]

Cserne, Peter. 2015. Making Sense of Nudge-Scepticism: Three Challenges to EU Law's Learning from Behavioural Sciences. In Nudge and the Law: A European Perspective. Edited by Anne-Lise Sibony. Oxford: Hart, pp. 279-99.

Di Porto, Fabiana, and Nicoletta Rangone. 2015. Behavioural Sciences in Practices. In Nudge and the Law: A European Perspective. Edited by Alberto Alemanno and Anne-Lise Sibony. Oxford: Hart, pp. 29-59.

Dietz, Thomas, Gerald T. Gardner, Jonathan Giligan, Paul C. Stern, and Michael Vandenbergh. 2009. Household actions can provide a behavioral wedge to rapidly reduce US carbon emissions. Proceedings of the National Academy of Sciences USA 106: 332-41. [CrossRef] [PubMed]

Dworkin, Gerald. 2010. Paternalism. In The Stanford Encyclopedia of Philosophy. Edited by Edward N. Zalta. Stanford: Metaphysics Research Lab. Available online: https:/ / plato.stanford.edu/entries/paternalism/ (accessed on 2 April 2021).

Dworkin, Gerald. 2016. Paternalism. In The Stanford Encyclopedia of Philosophy. Edited by Edward N. Zalta. Stanford: Metaphysics Research Lab. Available online: http://plato.stanford.edu/entries/paternalism/ (accessed on 20 August 2016).

Engel, Christoph, and Michael Kurschilgen. 2020. The Fragility of a Nudge: The power of self-set norms to contain a social dilemma. Journal of Economic Psychology 81: 102293. [CrossRef] 
Feldman, Yuval. 2018. The Law of Good People: Challenging States' Ability to Regulate Human Behavior. Cambridge: Cambridge University Press.

Feldman, Yuval, and Orly Lobel. 2015. Behavioral Trade-Offs: Beyond the Land of Nudges Spans the World of Law and Psychology. In Nudge and the Law: A European Perspective. Edited by Alberto Alemanno and Anne-Lise Sibony. Oxford: Hart, pp. 301-24.

Feldman, Yuval, and Orly Perez. 2009. How Law Changes the Environmental Mind: An Experimental Study of the Effect of Legal Norms on Moral Perceptions and Civic Enforcement. Journal of Law and Society 36: 501-35. [CrossRef]

Ferraro, Paul J., and Juan José Miranda. 2013. Heterogeneous treatment effects and mechanisms in information-based environmental policies: Evidence from a large-scale experiment. Resource and Energy Economics 35: 356-79. [CrossRef]

Frey, Bruno. 1998. Not Just for the Money. Cheltenham: Edward Elgar.

Furedi, Frank. 2011. Defending Moral Autonomy against an Army of Nudgers. Spiked (Online), January 20. Available online: https:/ / www.spiked-online.com/2011/01/20/defending-moral-autonomy-against-an-army-of-nudgers / (accessed on 30 March 2021).

Gneezy, Uri, and Aldo Rustichini. 2000. A fine is a price. Journal of Legal Studies 29: 1-17. [CrossRef]

Goldstein, Noah J., Robert B. Cialdini, and Vladas Griskevicius. 2008. A Room with a Viewpoint: Using Social Norms to Motivate Environmental Conservation in Hotels. Journal of Consumer Research 35: 472-82. [CrossRef]

Grüne-Yanoff, Till, and Ralf Hertwig. 2015. Nudge versus boost: How coherent are policy and theory? Minds and Machines 26: 1-35. [CrossRef]

Guala, Francesco, and Luigi Mittone. 2015. A Political Justification of Nudging. Review of Philosophy and Psychology 6: 385-95. [CrossRef]

Hage, Jaap. 2019. Law and Sustainability. In Sustainability and Private Law. Edited by Bram Akkermans and Gijs van Dijck. Den Haag: Eleven International Publishing.

Hausman, Daniel M., and Brynn Welch. 2010. Debate: To Nudge or Not to Nudge. Journal of Political Philosophy 18: 123-36. [CrossRef]

Ralph, Hertwig. 2017. When to consider boosting: Some rules for policy makers. Behavioural Public Policy 1: $143-61$.

Hertwig, Ralph, and Till Grüne-Yanoff. 2017. Nudging and Boosting: Steering or Empowering Good Decisions. Perspectives on Psychological Science 12: 973-86. [CrossRef] [PubMed]

Jolls, Christine, and Cass Sunstein. 2005. Debiasing through Law. No. W11738. Cambridge: National Bureau of Economic Research.

Jung, Janice Y., and Barbara A. Mellers. 2016. American attitudes toward nudges. Judgment and Decision Making 11: 62-74.

Kahneman, Daniel. 2011. Thinking Fast and Slow. London: Penguin.

Lehner, Matthias, Oksana Mont, and Eva Heiskanen. 2016. Nudging-A promising tool for sustainable consumption behavior? Journal of Cleaner Production 134: 166-77. [CrossRef]

Lepenies, Robert, and Magdalena Malecka. 2015. The institutional consequences of nudging-nudges, politics, and the law. Review of Philosophy and Psychology 6: 427-37. [CrossRef]

Mitchell, Gregory. 2004. Libertarian Paternalism Is an Oxymoron. Northwestern University Law Review $99: 1245$.

Moskin, Julia, Brad Plumer, Rebecca Lieberman, and Eden Weingart. 2019. Your questions about food and climate change, answered. The New York Times, April 30. Available online: https://www.nytimes.com/interactive/2019/04/30/dining/climate-changefood-eating-habits.html (accessed on 2 April 2021).

Nielsen, Anne Sofie Elberg, Henrik Sand, Pernille Sørensen, Mikael Knutsson, Peter Martinsson, Emil Persson, and Conny Wollbrant. 2016. Nudging and Pro-Environmental Behaviour. Copenhagen: Nordic Council of Ministers.

OECD. 2017. Tackling Environmental Problems with the Help of Behavioural Insights. Paris: OECD Publishing.

Oliver, Adam. 2015. Nudging, Shoving and Budging: Behavioral Economic-Informed Policy. Public Administration 93: 700-14. [CrossRef]

Osman, Magda, and Michelle Baddeley. 2019. Editors' Introduction-What Works: When and why are nudges stickly, scaleable and transferable? Journal of Behavioral Economics for Policy 3: 5-7.

Pichert, Daniel, and Konstantinous V. Katsikopoulos. 2008. Green defaults: Information presentation and pro-environmental behaviour. Journal of Environmental Psychology 28: 63-73. [CrossRef]

Rebonato, Riccardo. 2012. Taking Liberties. London: Palgrave Macmillan.

Reijula, Samuli, and Ralph Hertwig. 2020. Self-nudging and the citizen choice architect. Behavioural Public Policy 6: 119-49. [CrossRef]

Reisch, Lucia A., Cass Robert Sunstein, and Wencke Gwozdz. 2017. Viewpoint. Beyond Carrots and Sticks: Europeans Support Health Nudges. Food Policy 69: 1-10. [CrossRef]

Schnellenbach, Jan. 2016. A constitutional economics perspective on soft paternalism. Kyklos 69: 135-56. [CrossRef]

Schubert, Christian. 2014. Evolutionary Economics and the case for a constitutional libertarian paternalism. Journal of Evolutionary Economics 24: 1107-13. [CrossRef]

Schubert, Christian. 2015a. On the Ethics of Public Nudging: Autonomy and Agency. Available online: https://ssrn.com/abstract=26 72970 (accessed on 2 April 2021).

Schubert, Christian. 2015b. Opportunity and Preference Management. Economics and Philosophy 31: 275-95. [CrossRef]

Schubert, Christian. 2017. Green nudges: Do they work? Are they ethical? Ecological Economics 132: 329-42. [CrossRef]

Schubert, Christian, and Christian Cordes. 2013. Role Models that make you unhappy: Light paternalism, social learning and welfare. Journal of Institutional Economics 9: 131-59. [CrossRef]

Slovic, Paul. 1995. The construction of preference. American Psychologist 50: 367-71. [CrossRef] 
Stern, Paul C., Thomas Kietz, Gerald Gardner, and Jonathan V. Gilligan. 2010. Energy efficiency merits more than a nudge. Science 328: 308-9. [CrossRef]

Sugden, Robert. 2008. Why incoherent preferences do not justify paternalism. Constitutional Political Economy 19: 226-48. [CrossRef]

Sunstein, Cass. 2009. Green Nudges: An Interview with Obama Regulatory Czar Cass Sunstein. Grist.org, April 7. Available online: https://grist.org/article/2009-green-nudges-an-interview-with-obama-re/ (accessed on 2 April 2021).

Sunstein, Cass Robert. 2013. The Storrs Lectures: Behavioral Economics and Paternalism. Yale Law Journal 122: 1826-99. [CrossRef]

Sunstein, Cass Robert. 2014a. Why Nudge? The Politics of Libertarian Paternalism. New Haven: Yale University Press.

Sunstein, Cass Robert. 2014b. The Ethics of Nudging. Yale Journal on Regulation 32: 413-50. [CrossRef]

Sunstein, Cass Robert. 2015. Foreword: The Ethics of Nudging. In Nudge and the Law: A European Perspective. Edited by Alberto Alemanno and Anne-Lise Sibony. Oxford: Hart, pp. v-xviii.

Sunstein, Cass Robert. 2021. Green defaults can combat climate change. Nature Human Behavior 5: 548-49. [CrossRef] [PubMed]

Sunstein, Cass Robert, and Lucia A. Reisch. 2014. Automatically Green: Behavioural Economics and Environmental Protection. Harvard Environmental Law Review 38: 127. [CrossRef]

Sunstein, Cass Robert, and Richard H. Thaler. 2003. Libertarian Paternalism Is Not an Oxymoron. Available online: https://ssrn.com/ abstract $=405940$ (accessed on 2 April 2021).

Thaler, Richard, and Cass Sunstein. 2021. Nudge: The Final Edition. London: Allen Lane, Penguin Press.

Thorun, Christian, Jana Diels, Max Vetter, Lucia A. Reisch, Manuela Bernauer, Hans-Wolfgang Micklitz, Kai Purnhagen, Jan Rosenow, and Daniel Forster. 2017. Nudge-Ansätze beim nachhaltigen Konsum: Ermittlung und Entwicklung von Maßnahmen zum "Anstoßen" nachhaltiger Konsummuster. Berlin: ConPolicy-Institut für Verbraucherpolitik, pp. 1-142.

Tor, Avishalom. 2016. The Critical and Problematic Role of Bounded Rationality in Nudging. In Nudging-Possibilities, Limitations and Applications in European Law and Economics. Edited by Klaus Mathis and Avishalom Tor. Berlin: Springer International Publishing, pp. 3-10.

UK Cabinet Office. n.d. Mindspace. Influencing Behavior through Public Policy. London: Institute for Government.

UN Environmental Programme. 2017. Nudge to Action: Behavioural Science for Sustainability. Gigiri Nairobi: United Nations Avenue.

van Aaken, Anne. 2015. Judge the Nudge: In Search of the legal Limits of Paternalistic Nudging in the EU. In Nudge and the Law: A European Perspective. Edited by Alberto Alemanno and Anne-Lise Sibony. Oxford: Hart Publishing, pp. 83-112.

Vankatachalam, Lingappan. 2008. Behavioral economics for environmental policy. Ecological Economy 67: 640-45. [CrossRef]

Yayun, S., and Michael Faure. n.d. Behavioral Instruments in Environmental Policy. unpublished, in copy with the author. 